\title{
Técnicas de recuperación de material fílmico deteriorado: una revisión actualizada
}

\author{
Clara Sánchez-Dehesa Galán
}

\begin{abstract}
Resumen
El presente texto es una revisión de los tratamientos químicos que se aplican actualmente a materiales fílmicos deteriorados, para permitir su paso por las copiadoras y escáneres ,y acceder así a la información visual que contienen. A pesar de que la tecnología ha reducido al mínimo la intervención sobre los materiales originales, el coste de la misma hace que estos tratamientos no se hayan abandonado por completo.
\end{abstract}

La información sobre cada técnica se completa con sus contraindicaciones y anotaciones sobre la experiencia de profesionales.

\section{Palabras clave}

Conservación Fílmica, Materiales cinematográficos, Digitalización

\section{Recovery of damaged film material techniques: an updated review}

\section{Abstract}

This work is a review of the treatments that are being use today over deteriorated film materials, to be able to transport them through printers and scanners, in order to recover the information that they contains. Despite new technology has minimized the need for this treatments, cost are still high so they can not be neglected.

Treatment information is completed with drawbacks and experiences from professional technicians.

\section{Keywords}

Film Conservation, Film materials, Digitalization

http://dx.doi.org/10.5209/rev_CDMU.2013.v24.46279 


\section{INTRODUCCIÓN AL PROBLEMA}

En la actualidad la recuperación de las imágenes se desarrolla de forma digital, pero siempre se trabaja partiendo del material físico. Hemos visto en pocos años cómo la tecnología ha avanzado tanto que apenas son necesarias ya las labores de reparación de estos materiales, siguiendo la tendencia generalizada de mínima intervención sobre el material físico. Aunque ya existen escáneres que pueden procesar material muy deteriorado, estos aparatos siguen siendo extremadamente costosos, y por lo tanto hay una serie de tratamientos que todavía se utilizan para permitir el acceso al contenido fílmico.

La condición básica para recuperar las imágenes es ser capaces de transportar la película por los sistemas de arrastre de la positivadora o escáner. Para ello, el soporte debe presentar una serie de cualidades mecánicas y ópticas, que son las que permitieron en origen el desarrollo del sistema de captura, copia y proyección de la imagen en movimiento. Estas cualidades son estabilidad dimensional, resistencia mecánica, flexibilidad, cierto grado de rigidez, transparencia, ser incoloro y poseer un índice de refracción adecuado.

El deterioro de los materiales, ya sea por envejecimiento o provocado por agentes externos, hace que se modifiquen estas cualidades y por lo tanto, el acceso a la información se vea comprometido.

\section{SISTEMAS DE CAPTURA DE IMAGEN}

Todo el sistema de producción, copiado y visionado del material fílmico se basa en la exactitud de su diseño. La estandarización de formatos no sólo implica el ancho de la película sino la forma de las perforaciones, sus dimensiones y la distancia entre ellas. La estandarización completa de estas medidas se estableció en la década de los 50 del siglo pasado.

El positivado de películas se inició por el método de contacto, pero este sistema puede crear problemas cuando se trabaja con películas antiguas. El deterioro de los materiales fílmicos hace que se modifiquen sus dimensiones y por lo tanto, se salgan de los estándares de la maquinaria. La alternativa fue utilizar copiadoras ópticas. Se basan en la existencia de dos sistema de arrastre de película separados, pudiéndose adaptar cada uno al material que transporta. En el momento de la proyección de la imagen, ésta debe ser estabilizada mediante un garfio que desplaza la película fotograma a fotograma, y la mantiene en posición mientras se expone a la luz. Las copiadoras ópticas que trabajan con material deteriorado presentan juegos de rodillos intercambiables variando la distancia entre sus garfios. A día de hoy, existen copiadoras por contacto que pueden manejar material con un $1 \%$ de contracción, mientras que las copiadoras ópticas alcanzan el $2 \%$. Por encima, nos quedaría la digitalización mediante fotografías idividuales de cada fotograma.

\section{DETERIOROS QUE AFECTAN A LA RECUPERACIÓN DE LA IMAGEN}

Deterioros físicos provocados por la manipulación: roturas, pérdidas de soporte, desgarros, abrasión, rayas, etc. Estos deterioros crean problemas en el paso de la película por los rodillos de las positivadoras y escáneres. Las abrasiones en superficie presentan diferentes grados de refracción. La luz, al atravesar la película durante la proyección, las hace visibles en pantalla, y por lo tanto, entorpecen su visionado. 
Desprendimiento de emulsión o banda magnética: provocado normalmente por el envejecimiento o deterioro de la capa de adhesión entre soporte y emulsión. Comienza por los bordes pero puede producirse también en medio de la imagen. Esto supone la pérdida de información visual o sonora, además de complicar cualquier tratamiento de limpieza o escaneado.

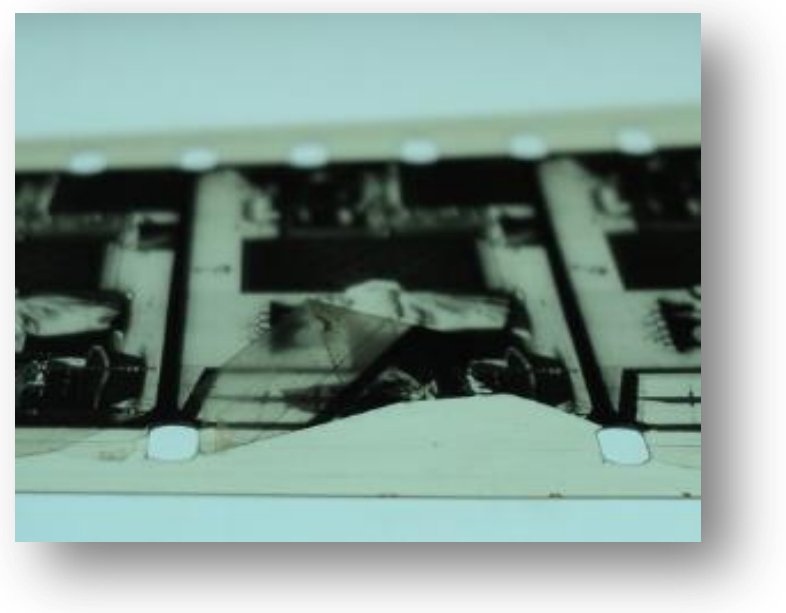

Imagen cortesía de George Eastman House

Pérdida de plastificantes del soporte: se da en los soportes de nitrato de celulosa y acetato de celulosa. Estas sustancias plastificantes son las que confieren al material físicas de las que hemos hablado. Se trata de sustancias muy volátiles, que se van perdiendo con el paso del tiempo. Esto provoca pérdida de flexibilidad, fragilidad, contracción y deformaciones del soporte.

Deterioro químico del nitrato de celulosa: sufre una hidrólisis que hace que la cadena de celulosa que lo forma se rompa, por la interacción de la humedad ambiental, y genera como residuo ácido nítrico. Este ácido es muy dañino, tanto para el propio material como para las personas que trabajan con él. El soporte se vuelve frágil y se contrae; el deterioro avanza y comienza a afectar a la imagen, desvaneciéndola o incluso destruyéndola por completo. Llegados a este punto la imagen no puede ser

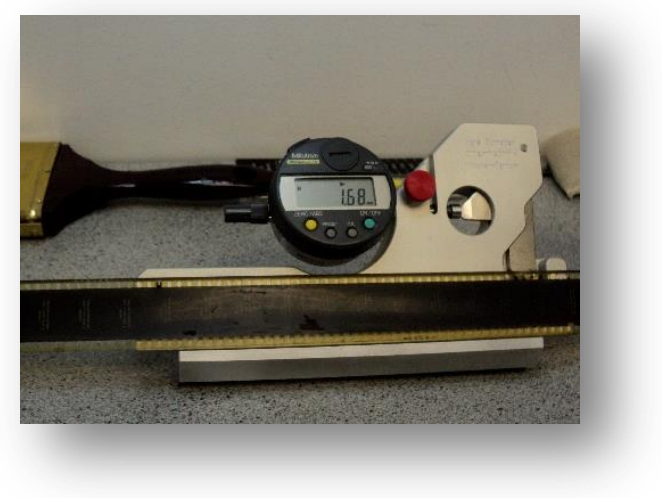
recuperada.

Medidor electrónico de contracción. Imagen cortesía de George Eastman House 
Deterioro químico de los acetatos de celulosa: se trata del conocido "síndrome del vinagre". Es un deterioro químico similar al que sufre el nitrato de celulosa, la humedad ambiental hace reacción con los componentes del soporte, y como residuo se desprende ácido acético. Tiene unos efectos muy identificativos, como el olor intenso a vinagre, pérdida de flexibilidad, contracción, deformación y amarilleado.

Deterioro químico de la gelatina: provocado por el envejecimiento natural o por la acción de los gases químicos derivados de los deterioros del nitrato o del acetato de plata. La gelatina pierde las cualidades de flexibilidad, capacidad de absorción de humedad y resistencia.

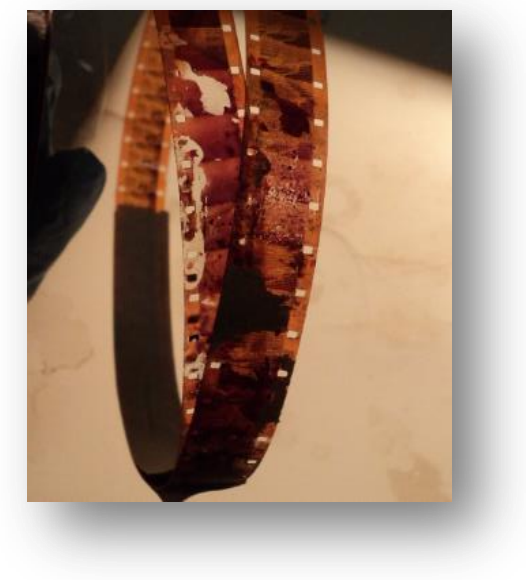

Imagen cortesía de George Eastman House

Deterioro biológico de la gelatina: la combinación de altas temperaturas y elevados niveles de humedad relativa favorecen el crecimiento de hongos o bacterias. Estos organismos desnaturalizan la gelatina y la convierten en soluble. Es por eso que antes de realizar cualquier tratamiento acuoso, se debe comprobar que el material no presenta este tipo de deterioro.

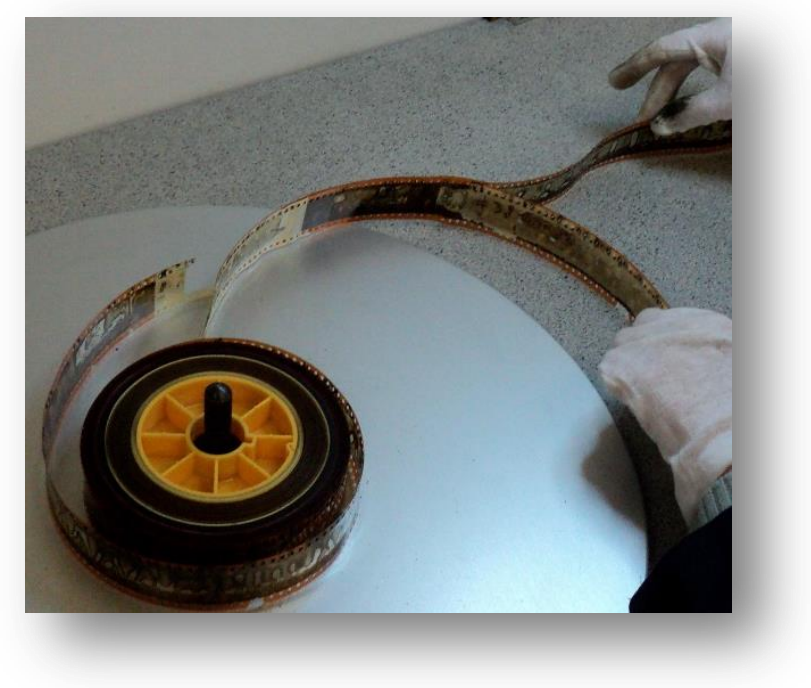

Imagen cortesía de George Eastman House 
Rollos en bloque: se trata de un problema que tiene diversas causas, combinación de elevada humedad relativa y presión, exposición a altas temperaturas, descomposición del soporte o deterioro de la banda magnética de sonido. El resultado es siempre un bloque de película que no puede ser desenrollado y por lo tanto no se puede acceder al contenido.

Deterioro de la imagen de plata: debido a la presencia de humedad ambiental y gases contaminantes, la plata que forma la imagen en las películas en blanco y negro puede verse deteriorada por oxidación o sulfuración. Esto da como resultado un desvanecimiento de la imagen y pérdida de información en los detalles. Además, la plata puede migrar dentro de la emulsión y depositarse en la superficie de la misma creando el conocido espejo de plata.

Deterioro de la imagen en color: el principal problema es el desvanecimientos, principalmente de los procesos cromogénicos donde las tintas son creadas durante el revelado de la película. Las tintas utilizadas en el proceso de Tecnicolor son mucho más estables.

\section{TÉCNICAS DE RECUPERACIÓN LA IMAGEN}

Los manuales especializados en preservación fílmica suelen incluir una breve explicación de la metodología y las fórmulas a utilizar. Cómo ejemplo tenemos el manual de Read and Mayer 2000: pág. 252 - 254, que dedica el capítulo 24 a Deshrinkage and other treatmenst. Estos tratamientos son: deshrinkage (podría traducirse por "desencogimiento"), relavado, tratamientos en cámara de vacío para el redimensionado, la rehumidificación y el proceso llamado NO - EN, ya en desuso.

Un manual más actual que está pendiente de publicación, pero al que he tenido acceso para esta revisión, es el Film Preservation Handbook, del National Film and Sound Archive of Australia. En este caso el capítulo se titula Advance Conservation Treatments, recoge la mayoría de los tratamientos mencionados en el anterior, y alguno nuevo: relavado, unblocking, adherimiento de la banda sonora que se haya desprendido y redimensionado con tres tipos de fórmula

Además de recopilar información que aparece en los manuales, me parece importante incluir la visión de aquellos que trabajan día a día con estos materiales. Para ello he contado con la colaboración de Mick Newnham (National Film and Sound Archive of Australia), Ulrich Ruedel (British Film Institute), Nino Dzandzava (Georgian National Film Center), Reto Kromer (AV Preservation - Laboratorio), Janis Allen (Cinema Arts) y Dean Pliones (ColorLab).

A continuación se presenta la lista de técnicas de recuperación del material deteriorado que se están utilizando hoy en día. La descripción que sigue a cada técnica no recoge la fórmula exacta. Si se quisiera desarrollar el procedimiento de forma científica, recomiendo consultar los textos mencionados. Después de la descripción del tratamiento, le sigue un punto de problemas que puede provocar y otro punto con las experiencias compartidas por los profesionales antes mencionados. 


\section{Readherir}

Si estamos hablando de la capa de gelatina, que se ha desprendido del soporte, la forma de adherir estos fragmentos y evitar que se pierdan es mediante el uso del cemento de empalme. Aplicado sobre el soporte, se coloca la película de emulsión desprendida y se presiona durante un momento para facilitar su adhesión.

Otro caso de desprendimiento sería el de la banda sonora que viene aplicada como tira autoadhesiva sobre la película. Para volver a adherir la película que puede haberse desprendido se utiliza el disolvente metil etil cetona (MEK) sin diluir, aplicado con un pequeño pincel. Se trata de un trabajo muy minucioso y debe realizarse con mucha precisión. Se aplicará una ligera presión para asegurar la banda.

- Problemas: los fragmentos de emulsión pueden perderse en el proceso o durante el transporte en las copiadoras. Si no se realiza con cuidad pueden quedar restos de adhesivo y ensuciar la película. La durabilidad del tratamiento dependerá mucho de cada material, pero el objetivo primordial es captar la mayor cantidad de información durante el escaneo para reducir la posproducción.

- Experiencias: Se trata de un trabajo muy meticuloso. Los técnicos de archivo y de laboratorio, dan gran importancia a este tipo de reparaciones en la película, que debe ser realizada por especialistas.

\section{Redimensionado}

Es muy agresivo y se recomienda como último recurso en películas muy encogidas. Se somete al material a un tratamiento químico que afecta al plástico de la base y que hace que recupere momentáneamente sus dimensiones originales. Este tratamiento se puede aplicar a acetatos de celulosa que no presenten daño biológico o visible descomposición, pero sí un notable encogimiento o deformación del soporte.

La FIAF propone como fórmula la que combina acetona, glicerina y agua. Los porcentajes varían según los casos.

Para las películas sobre nitrato de celulosa, se propone el uso de alcanfor. Esto exige que la película esté enrollada en un carrete metálico porque el alcanfor puede afectar al plástico de los carretes y los núcleos. Se introduce una pastilla de alcanfor en una lata de metal con el carrete de película. Se debe dejar cerrado por varios días. Otra opción es disolver el alcanfor en aceite de oliva. Humectar un disco de papel libre de ácido con este aceite y colocarlo en el fondo de una lata de metal, cerrar la tapa y dejar actuar unos días. Este tratamiento trata de recuperar el plastificante que se ha perdido y que originariamente se había utilizado en el soporte, el alcanfor.

- Problemas: Se trata de una solución temporal, breve y que requiere digitalizar de inmediato. Suele provocar, posteriormente, un nuevo encogimiento si cabe más severo, causando daños permanentes en el material. El resultado y los efectos secundarios varían mucho según las películas. Siempre que se trata de tratamientos acuosos, hay riesgo de un deterioro biológico. En el caso de algunas películas de diacetato de celulosa, se ha notado que la base se vuelve opaca, blanquecina, perdiendo transparencia y haciendo por lo tanto imposible el duplicado. Una vez la película se seca, la transparencia se recobra, pero el encogimiento y la deformación se vuelven más severos. Favorece por lo tanto el desprendimiento de la capa de emulsión. El riesgo que se corre es que la película en ocasiones se vuelve demasiado frágil y puede ser fácilmente desagarrada si los aparatos de arrastre no están bien ajustados. 
- Experiencia: desde los archivos se recomienda no utilizar esta técnica, es demasiado agresiva e imprevisible como para arriesgar el material, aunque admiten que han tenido buenos resultados con la fórmula que presenta la FIAF pero también algunos desastres. La actitud de los laboratorios frente al redimensionado es, por el contrario, positiva. No todos los laboratorios la llevan a cabo, pero los que la realizan presentan buenos resultados. El proceso se desarrolla bajo el control constante de un técnico.

\section{Rehumidificación}

Busca devolver al material la humedad perdida. Esta técnica consiste en colocar la película enrollado con poca tensión en una cámara de vacío, con una base de agua destilada. Se coloca el rollo suspendido sobre el agua y se deja 24 horas o hasta que se note una mejoría en la flexibilidad del material. Se suele añadir un formaldehído, para prevenir el desarrollo de hongos o bacterias, y en ocasiones algún plastificante. Se utiliza en materiales que presentan un aspecto frágil y quebradizo, para mejorar su flexibilidad. Es un proceso muy similar al del redimensionado pero no consigue la recuperación de las dimensiones iniciales.

- Problemas: aunque se añada un formaldehído, el deterioro biológico siempre está presente. Los problemas que se describen en el redimensionado en los soportes de diacetato pueden aparecer también durante este tratamiento.

- Experiencia: se trata de un proceso que se utiliza muy poco, y que se confunde con el redimensionado.

\section{Relavado}

Consiste en realizar el proceso de lavado de la película en medio acuoso para eliminar cualquier suciedad o resto que sea soluble en agua es susceptible de ser eliminado durante el proceso. El relavado puede favorecer el rellenado de abrasiones o rayas en la emulsión, al provocar su hinchamiento mediante absorción. Es eficaz en las abrasiones más superficiales y otros daños físicos poco profundos de la emulsión.

Este tratamiento no sirve para eliminar manchas de grasa, huellas dactilares o restos de aceite de proyección, pero puede ayudar a disminuir el ferrotipado.

El tratamiento tiene que ser llevado a cabo en una máquina de procesado para que sea realizado de forma segura. Pero esta máquina debe ser adaptada y ajustada para reducir la tensión por lo tanto hay que recurrir a un laboratorio especializado.

Es crucial también llevar a cabo un buen secado de la película, en una cabina de secado que no exceda de los 35 ․ C. Si supera esta temperatura, la humedad puede quedar atrapada en la película y acelera los procesos químicos de deterioro.

- Problemas: debilitamiento de la base por absorción de humedad, daño en las reparaciones de la película y empalmes. Solubilidad de tratamientos que pueda presentar en superficie o adiciones con tintas, por eso hay que tener especial cuidado si se está trabajando con procesos de color antiguos. El aumento de los niveles ácidos que pueden afectar a la solubilidad de la emulsión, sobre todo en películas muy antiguas. Reticulación de la emulsión, esto se produce si hay algún cambio en la temperatura en los tanques de lavado, la emulsión puede sufrir lo que se llama un shock térmico y crear esta retícula visible con luz rasante. 
- Experiencia: en general es un tratamiento con buena acogida, que se utiliza con al finalidad de reducir la suciedad y daños superficiales de la película. Aun así, hay laboratorios, como AV Preservation que llevan años sin aplicarlo.

\section{Unblocking}

En ocasiones los rollos de película quedan como un bloque, debido a que las espiras se han adherido entre sí. Esto se puede haber producido por diversas causas, una de ellas es estar sometidos a condiciones de alta humedad relativa, y por lo tanto, en un rollo que está enrollado con cierta presión, al absorber la emulsión humedad, se hincha y puede quedarse adherida al soporte. La forma de desenrollarlo es mediante la aplicación de una solución acuosa de polimetafosfato de sodio.

Otro caso posible sería un rollo de película adherido debido a elevadas temperaturas. Se puede aplicar el mismo tratamiento, realizando previamente una limpieza de los residuos superficiales con alcohol isopropílico y eliminación de restos fundidos de carrete de plástico si los hubiera. El tratamiento es efectivo si el daño no es muy grave.

Después del tratamiento se debe hacer un relavado de la película y un secado adecuado.

Un tercer rollo en bloque que podemos encontrarnos con el material de acetato, es que al descomponerse, uno de sus aditivos migra hasta la superficie de la película creándose una capa similar al cemento entre las espiras de película. El tratamiento para separarlo consiste en disolver este cemento. El aditivo que migra es trifenil fosfato (TPP) que es soluble en etanol. Este disolvente puede dañar la película, produciendo un encogimiento prematuro, así que el etanol se mezcla con alcohol isopropílico. Variando la concentración de estos dos agentes, y mediante la aplicación directa puntual (con cuentagotas) en las zonas deseadas se puede ir separando la película.

- Problemas: esta mezcla de químicos crea derivados acuosos que pueden afectar a la gelatina, haciéndola soluble al agua. Por lo tanto no se recomienda realizar un lavado posterior de los materiales así tratados.

- Problemas: la solubilidad de la emulsión, el crecimiento de hongos o bacterias alrededor de la película y problemas en la manipulación; enrollar película mojada requiere destreza, será necesario práctica previa con material no histórico.

Una última forma de rollo en bloque sería producida por las películas que presentan banda magnética. Cuando se trata de una banda magnética aplicada mediante el método de dispersión de alta viscosidad, se utiliza una solución de alcohol isopropílico y Photo-Flo@ de Kodak para separarlas, procurando aplicarla sólo en la zona de la banda magnética.

- Problemas: la separación puede suponer ciertas pérdidas de emulsión e información en el proceso, pero lo posibles daños no son significativos, si tenemos en cuenta que nos permite leer la pista.

- Experiencia: se trata de un tratamiento muy usado en la actualidad, algunos laboratorios afirman que tienen siempre al menos un rollo de película en proceso. 


\section{CONCLUSIONES}

Todas las técnicas que se han mencionado, actúan sobre el soporte de la película La recuperación de la información de la imagen dañada se está tratando desde el ámbito digital. En esta dirección podemos encontrar publicaciones técnicas interesantes en el archivo del SMPTE. Por ejemplo, durante las conversaciones con los profesionales de archivos, se ha comentado el uso de un rango más amplio de longitudes de onda para capturar la imagen en películas de color desvanecidas.

Tanto en los manuales como en los comentarios de los profesionales, encuentro algo de confusión entre técnicas de rehumidificación y redimensionado. El laboratorio Colorlab denomina a su tratamiento replastificación, pero este se asemeja bastante a los anteriores. Las fórmulas se suelen modificar para un mejor resultado según el tipo de material.

La actitud generalizada es mantener la intervención sobre el material original al mínimo, esto también incluye las labores de reparación, que son necesarias para que la película pase por los sistemas de arrastre sin dañarse. Los laboratorios especializados son los lugares para realizar estas intervenciones, cuentan con la maquinaria necesaria y sobre todo con la experiencia. El trabajo en los archivos debe ser el de prevenir estos deterioros y detectarlos en sus etapas iniciales para que no sea necesaria una acción tan agresiva sobre las películas.

El objetivo de la industria debería ser el abaratamiento de los escáneres que presentan un sistema de arrastre sin garfios y con tensión regulable, como el que lanzó al mercado ARRI en 2010: ARRISCAN Sprocketless. y REFLEX Technologies poco después. En la página web de ARRI se pueden apreciar las posibilidades que sto supone. http://www.arri.com/archive_technologies/archive_challenges_and_solutions/

Creo que este tema, tratado ahora de forma rápida, puede dar lugar a cuestiones interesantes, si se sigue la línea de entrevistas a los profesionales.

\section{REFERENCIAS BIBLIOGRÁFICAS}

Case, Dominic. Film Technology in Post Production. 2nd edition. Burlington, Mass: Focal Press. 2001. Inédito. Film Preservation Handbook, del National Film and Sound Archive of Australia.

Read, Paul and Meyer, Mark-Paul. Restoration of Motion Picture Film. Oxford. Butterworth Heinemann. 2000.

Amo, Alfonso del. Clasificar para preservar. México. Cineteca Nacional. 2006.

Bernbach, David. Arri News. Arriscan Archive: New tools for the most comprehensive restoration scan package on the market. $\quad 2010 \quad$ Pag 47. http://arrilightingrental.com/downloads/downloads/ARRI\%20News\%20April\%202010

Reflex Tecnologies Reflex Technologies Showcases Unique Alaskan Project to AMIA Attendees Company shows scanned footage from 1932 Lindley-Liek Expedition. Burkbank, California, 2012. http://reflextechnologies.com/news/press-releases/

\section{AGRADECIMIENTOS}

Quiero dedicar un pequeño párrafo a agradecer a los profesionales, tanto de archivos como de laboratorios, que amablemente han respondido a mis preguntas y gracias a los cuales el texto adquiere interés. 